\title{
A potential risk from under-recognized perioperative anticoagulation from dalteparin used for extracorporeal circuit anticoagulation during hemodialysis
}

\author{
M. Kwesi Kwofie, MD, FRCPC (1) Jo-Anne Wilson, BSc Pharm, ACPR, PharmD
}

Received: 22 June 2019/Revised: 25 July 2019/ Accepted: 5 August 2019/Published online: 8 August 2019

(c) Canadian Anesthesiologists' Society 2019

\section{To the Editor,}

There is a common misconception that dalteparin sodium, a low molecular weight heparin (LMWH), should not be used in patients with severe chronic kidney disease. ${ }^{1}$ Nevertheless, dalteparin sodium is commonly used during hemodialysis and has a Health Canada indication to prevent clotting in the extracorporeal circuit (ECC) during hemodialysis, ${ }^{2}$ replacing unfractionated heparin (UFH). The dose typically used (twice weekly) is 2,500-5,000 IU administered intravenously into the arterial side of the dialyzer. Nevertheless, some patients may require doses higher than 5,000 IU (with some cases exceeding 10,000 IU iv). Despite this, there are no perioperative cases of harm from residual dalteparin sodium after hemodialysis.

There are no recommendations within existing guidelines regarding direct management of the hemodialysis population undergoing neuraxial anesthesia or any other high bleeding risk procedures. In instances where substantial clinical data are absent, the American Society of Regional Anesthesia (ASRA) guidelines can be consulted; these are based upon a synthesis of the pharmacologic evidence. ${ }^{3}$ In general, ASRA recommends that patients on therapeutic doses of an anticoagulant abstain for five half-lives of the relevant medication, while for prophylactic doses they suggest an abstinence period of

M. K. Kwofie, MD, FRCPC ( $)$

Department of Anesthesia, Pain Management and Perioperative Medicine, Dalhousie University, Halifax, NS, Canada

e-mail: kwesi.kwofie@dal.ca

J.-A. Wilson, BSc Pharm, ACPR, PharmD

Division of Nephrology, Nova Scotia Health Authority, Faculty

of Health, Dalhousie University, Halifax, NS, Canada two half-lives. The mean (standard deviation) half-life of dalteparin sodium in hemodialysis patients receiving 5,000 IU iv is 5.7 (2.0) $\mathrm{hr}^{2}{ }^{2}$ There does not appear to be saturable elimination or bioaccumulation at doses of 5,000 IU or less per day ${ }^{4}$ and its ability to be dialyzed is unlikely. Thus, using a five half-lives approach, approximately $30 \mathrm{hr}$ of abstinence would be required. Nevertheless, if only two mean half-lives are used, then approximately $12 \mathrm{hr}$ of abstinence would be required. If two of the highest range of half-lives were used, then about $20 \mathrm{hr}$ of abstinence would be required.

It would appear that in the absence of any published guidelines, a reasonable period of abstinence from a single dose of dalteparin sodium less than 5,000 IU iv during hemodialysis might be somewhere between $20-30 \mathrm{hr}$, in the absence of other anticoagulant medications or other bleeding tendencies. Nevertheless, it is important to remember that uremic patients have platelet dysfunction that is only partially mitigated by dialysis.

It is possible that a patient having had dialysis the evening before their surgery might present as the first scheduled case on an elective surgical list. This might lead to the patient being $12 \mathrm{hr}$ (or less) from their most recent dalteparin dose. If a surgical procedure is planned and communicated to the dialysis team, then other options such as the use of saline flushes ${ }^{5}$ (instead of an anticoagulant), a regional citrate technique, or UFH iv could be used for ECC management during the immediate preoperative dialysis session. If anticoagulation can be withheld for a single dialysis session on the day before the surgery, then most patients would be free of anticoagulation for approximately $72 \mathrm{hr}$.

It should be noted that other LMWHs have differing pharmacologic properties with longer half-lives, increased renal dependence, and increased tendencies towards 
Table Recommendations for extracorporeal circuit management during perioperative dialysis

1. Create a route for effective communication between the perioperative team and the dialysis team.

2. If dalteparin sodium has been used at a dose of 5,000 IU or less, then a period of 20-30 hr may be required for hemostatic function to return to baseline. Higher doses may require a longer interval.

3. Consider use of alternative anticoagulation without a long duration such as a regional citrate technique or unfractionated heparin.

4. Consider use of saline flushes instead of an anticoagulant.

bioaccumulation. Knowledge of one preparation should not be generalized to the entire class of medications. ${ }^{4}$

In summary, intravenous dalteparin sodium is frequently used to prevent ECC clotting during hemodialysis in many dialysis units across Canada. There is a potential for unintended (and under-appreciated) prolonged anticoagulation that could theoretically lead to clinical issues in the perioperative period for hemodialysis patients having surgical procedures. The duration of abstinence required for hemodialysis patients who receive dalteparin sodium before neuraxial procedures is not addressed by any current nephrology, regional anesthesia, or perioperative medicine guidelines. In most cases, anticoagulant medications can be safely withheld during a dialysis session and patients can receive saline flushes to prevent ECC clotting. Optimal communication between the dialysis unit and the anesthesiologist during the preoperative assessment may help to avoid unintended, unrecognized, prolonged preoperative anticoagulation.
Conflicts of interest None declared.

Editorial responsibility This submission was handled by Dr. Hilary P. Grocott, Editor-in-Chief, Canadian Journal of Anesthesia.

\section{References}

1. Alvarez G, Chrusch C, Hulme T, Posadas-Calleja JG. Renal replacement therapy: a practical update. Can J Anesth 2019; 66: 593-604.

2. Pfizer Canada Inc. Fragmin ${ }^{\circledR}$ Product Monograph (Canada). Available from URL: https://www.pfizer.ca/sites/g/files/g10050 796/f/201810/FRAGMIN_PM_E_210778_18Oct2018.pdf (accessed July 2019).

3. Horlocker TT, Vandermeuelen E, Kopp SL, Gogarten W, Leffert LR, Benzon HT. Regional Anesthesia in the Patient Receiving Antithrombotic or Thrombolytic Therapy: American Society of Regional Anesthesia and Pain Medicine Evidence-Based Guidelines (Fourth Edition). Reg Anesth Pain Med 2018; 43: 263-309.

4. Atiq F, van den Bemt PM, Leebeek FW, van Gelder T, Versmissen $J$. A systematic review on the accumulation of prophylactic dosages of low-molecular-weight heparins (LMWHs) in patients with renal insufficiency. Eur J Clin Pharmacol 2015; 71: 921-9.

5. Zimbudzi E. Intermittent saline flushes or continuous saline infusion: what works better when heparin-free dialysis is recommended? Int J Nephrol Renovasc Dis 2013; 6: 65-9.

Publisher's Note Springer Nature remains neutral with regard to jurisdictional claims in published maps and institutional affiliations. 